doi:10.12662/2359-618xregea.v9i3.p81-97.2020

ARTIGOS

\title{
A REGIONALIDADE E A FORMAÇÃO DE ADMINISTRADORES: UM ESTUDO NO NORDESTE BRASILEIRO
}

\author{
REGIONALITY AND TRAINING OF \\ ADMINISTRATORS: A STUDY IN NORTHEAST \\ BRAZIL
}

\section{RESUMO}

Este artigo objetiva analisar a formação do administrador no Nordeste do Brasil por meio das dimensões histórico-política, estrutural-institucional e cultural-social. O método caracteriza-se pela perspectiva interpretativista e de cunho qualitativo, em que participaram da pesquisa nove docentes envolvidos com a criação e o desenvolvimento do curso de Administração na localidade. As entrevistas subsidiaram a categorização dos discursos divididos nas dimensões apresentadas. Os resultados revelaram que as dimensões do ambiente de aprendizagem efetivamente exercem um papel preponderante no ensino de Administração. Por fim, conclui-se que uma formação regionalizada se constitui em uma alternativa para promover a aproximação entre ensino e ambiente de aprendizagem de maneira a alinhar-se com as possibilidades de atuação profissional em Administração no Nordeste.

Palavras-chave: Ensino de Administração. Região Nordeste. Dimensões do ambiente de aprendizagem. Docentes. Formação Regionalizada.

\begin{abstract}
This article aims to analyze the formation of the administrator in the Northeast of Brazil through the historical-political, structural-institutional and cultural-social dimensions. The method is characterized by an interpretative and qualitative perspective, in which nine professors involved in the creation and development of the Administration course in the locality participated in the research. The interviews subsidized the categorization of discourse divided in the presented dimensions. The results revealed that the dimensions of the learning environment effectively play a preponderant role in the teaching of Administration. Finally, it was concluded that a regionalized training constitutes an alternative to
\end{abstract}

Thales Batista de Lima thalesufpb@gmail.com Doutor em Administração (PPGA/UFPB). Professor Adjunto III do DCSA/CCAE/ $U F P B$.

Universidade Federal da Paraíba. João Pessoa - PB - BR. 
promote the approximation between teaching and learning environment in order to align with the possibilities of professional performance in Administration in the Northeast.

Keywords: Education in Administration. Northeast Region. Environmental Dimensions of the Learning Environment.Teachers. Regionalized Training.

\section{INTRODUÇÃO}

O ensino de Administração ainda continua enfrentando dificuldades para a integração das construções conceituais com a prática organizacional e o contexto da atuação profissional. Desse modo, a Administração foi-se desvinculando de sua própria concepção de ciência. Porém, no Brasil, a área só foi reconhecida como científica nos anos de 1960, quando a formação do administrador foi regulamentada. Antes disso, a ciência da Administração era confundida com a ciência econômica (NICOLINI, 2003), cuja influência do modelo de ensino do País é oriunda das escolas de Administração norte-americanas, predominantemente gerencialistas, com traços das ciências exatas e econômicas.

As políticas públicas de educação ligadas à qualificação profissional em geral e o ensino de Administração em particular devem pensar ações estratégicas de desenvolvimento regional que levem, em consideração, aspectos contextuais para que o conhecimento seja aplicável, alinhando um processo de ensino e aprendizagem como teórico-prático para a formação de profissionais mais qualificados para atender às demandas regionais sem perder de vista a sua amplitude nacional e internacional.

O ambiente econômico, político e social de um país ou região tem impacto nas políticas públicas de educação do País, que afetam os investimentos em infraestrutura, pesquisa e formação profissional e nas instituições de ensino superior, tanto pública, quanto instituição privada, já que os reflexos desse contexto podem comprometer o desenvolvimento regional.

No caso específico do ensino de Admi- nistração, percebe-se que sua função no desenvolvimento econômico, político e social é fundamental, uma vez que a formação e a qualificação de profissionais podem contribuir para o aumento da competitividade e da inovação em termos de tecnologias de gestão, por meio de estratégias para superar cenários de instabilidade e crises no campo organizacional. Entretanto, Colli e Chagas (2018) atentam que os estudantes, em geral, questionam a visão limitada que ocorre no ensino de Administração no tocante às funções e às possibilidades de atuação de um administrador na atualidade.

Assim, é nítida a lacuna de estudos que alinhem a relevância da teoria e prática simultaneamente para o ensino de Administração, sobretudo, em contextos regionais, pois o ensino ainda é visto com discrepância entre o que se aprende e o que se atua devido às particularidades contextuais desconsideradas nos arcabouços teóricos vistos em sala de aula (LIMA; SILVA, 2015). Nesse sentido, este estudo torna-se importante por entender como ocorre a trajetória da educação em administração em uma região do País, contribuindo, como uma alternativa para conscientizar os agentes públicos de que a educação superior é uma política de estado e necessita ser priorizada em ambientes de crise.

Considerando-se o período 2005-2015, o número de ingressantes em cursos de graduação aumentou $57,46 \%$ no país. No que se refere ao curso de Administração, é um dos que tem se propagado pelo território, representando, recentemente, 800 mil matriculados, conforme dados do Instituto Nacional de Estudos e Pesquisas Educacionais Anísio Teixeira (INEP) relativos ao Censo da Educação Superior no Brasil em 2015.

Evidencia-se que há um aumento da procura pela formação superior no Nordeste, possivelmente em decorrência de mudanças percebidas nas exigências profissionais do mercado de trabalho. No entanto, pode-se questionar a capacidade dessa formação para proporcionar um conteúdo condizente com o seu ambiente de aprendizagem do aluno, ou seja, com o mundo do trabalho local. 
Dessa forma, este estudo pretende contribuir com o elo teoria e prática no ensino de Administração da região estudada, por meio de seu ambiente de aprendizagem, podendo favorecer uma formação qualificada ao se considerar a realidade da gestão do local. Nesse sentido, este artigo objetiva analisar a formação do administrador no Nordeste do Brasil por meio das dimensões histórico-política, estrutural-institucional e cultural-social.

\section{REFERENCIAL TEÓRICO}

\subsection{O ENSINO DE ADMINISTRAÇÃO NO NORDESTE BRASILEIRO}

Sabe-se que a introdução do ensino superior no Brasil ocorreu em 1808, ainda na época imperial, de forma precária e dissociada da prática. Somente em 1827, surgiu a primeira normatização de acesso ao ensino superior no País (SAVIANI, 2010) e, paulatinamente, foram introduzidos outros cursos superiores. Como o Brasil pertence a um grupo de países que consideravam, durante parte do século $\mathrm{XX}$, a industrialização como o caminho seguro e natural para o desenvolvimento econômico (VALE; BERTERO; SILVEIRA, 2013), passou-se a investir no curso de Administração para adotar modelos de gestão que contribuíssem para esse processo. Assim, o surgimento do curso é consequência da ideia de um modelo desenvolvimentista, em que se pretendia estimular o desenvolvimento econômico do País por meio da viabilização de práticas de gestão.

Dessa forma, o curso de Administração surge em 1941 na Escola Superior de Administração de Negócios (ESAN/SP), inspirado no modelo do curso da GraduateSchoolof Business Administration da Universidade de Harvard. Em seguida, é criada a Faculdade de Economia, Administração e Contabilidade da Universidade de São Paulo. Na década de 1950, aparece a primeira faculdade com foco na Administração Pública pela Escola Brasileira de Administração Pública e de Empresas da Fundação Getúlio Vargas (EBAPE/FGV), no Rio de Janeiro. Somente em 1965, a profissão é regulamentada, conforme dados do Conselho Federal de Administração, por meio da Lei $\mathrm{n}^{\circ} 4.769$, de 9 de setembro de 1965. A partir da promulgação dessa lei, o acesso ao mercado profissional passa a ser privativo dos portadores de títulos expedidos pelo sistema universitário.

No período compreendido entre os anos 1940 a 1960, houve uma proliferação de cursos específicos para Administração Pública que acompanhavam a diversificação de seu modus operandi. O ensino de graduação em Administração no Nordeste brasileiro surgiu em 1959, na UFBA (FISCHER, 1984; RIBEIRO, 2011), com uma formação orientada para a Administração Pública. Na verdade, o curso de Administração com ênfase em finanças, segundo Ribeiro (2011), foi criado em 1931 no estado da Bahia, mas foi substituído pelos cursos de Ciências Econômicas e Contábeis no ano de 1945. Entretanto, em 1959, foi criada a escola de Administração, antes mesmo da mudança de denominação de Universidade da Bahia para Universidade Federal da Bahia, que ocorreu em 1965.

No estado do Ceará, o curso mais antigo é o da Universidade Estadual do Ceará (UECE), criado em 1957. Esse foi estruturado a partir do modelo da Escola de Administração do estado de São Paulo da FGV e replicado no estado para um viés de Administração Pública. O curso na Universidade Federal do Ceará (UFC) somente foi criado na década de 1970. Outro caso interessante é o da Universidade Federal do Maranhão (UFMA), em que o curso de Administração só foi criado nos anos 2000, porém já se fazia presente no estado, desde 1968 pela Universidade Estadual do Maranhão (UEMA). Constata-se que, nos estados do Ceará e do Maranhão, o surgimento dos cursos de Administração ocorreu nas Universidades Estaduais, diferentemente dos outros estados da região, onde tais cursos surgiram nas Universidades Federais.

A maioria dos projetos pedagógicos dos cursos da região era orientada para a área de Administração Pública. O impulso para essa 
vertente ocorreu nas universidades federais na medida em que, aos processos administrativos do Governo, agregavam-se as funções econômicas e sociais do estado (COELHO, 2008). Entretanto, a partir da década de 1970, com o boom econômico, houve uma intensificação da oferta do ensino de Administração de Empresas e a vertente da Administração Pública passou a ser uma adaptação daquela. O setor público em geral é tomado pela noção gerencialista, assemelhando o campo do saber de ambas as vertentes (COELHO; NICOLINI, 2010), como se não houvesse distinções em virtude do contexto particular de cada uma.

Percebe-se que o surgimento da graduação em Administração no Nordeste ocorre concomitantemente às mudanças econômicas. Araújo (2004) relata que, a partir dos anos 1970, impulsionadas pelos incentivos fiscais, por investimentos de empresas estatais do porte da Petrobrás (na Bahia) e da Vale do Rio Doce (no Maranhão), complementados com créditos públicos particularmente do Banco Nacional de Desenvolvimento (BNDES) e do Banco do Nordeste do Brasil (BNB) e com recursos próprios de importantes empresas locais, nacionais e multinacionais, as atividades urbanas e industriais ampliaram sua participação no ambiente econômico do Nordeste e passaram a comandar o crescimento da produção nessa região brasileira, rompendo a fraca dinâmica existente anteriormente.

Nas décadas seguintes de 1980 e 1990, o País vivencia reformulações na sua própria ideia de desenvolvimento, também influenciada pelo entendimento do mercado externo, tornando-se um estado mais regulador (COELHO, 2008). Tais mudanças atingem o ambiente organizacional e, consequentemente, também o ensino. Logo, Fischer (1993) alerta que o ensino de Administração deveria formar alunos capazes de gerenciar as crises do País em uma economia vista como moderna.

O ambiente social do Nordeste, tido como precário, na verdade, conforme Araújo (2004), é alimentado pelas oligarquias da região, assim como o domínio que os representantes dos estados exercem no ambiente político, preservando velhas estruturas, como a própria questão fundiária e da seca, que implica nas formas de atuação das organizações na região. Segundo a autora, a modernização no Nordeste brasileiro é conservadora e acontece de forma heterogênea entre os estados, pois alguns não conseguiram seguir o mesmo fluxo desenvolvimentista que os demais, como é o caso dos estados da Paraíba e de Piauí, por exemplo.

Desse modo, o ensino recebe a influência desse panorama, cuja realidade contextual difere, até mesmo, entre os estados e ainda mais quando vistos regionalmente. A realidade social revela um Nordeste heterogêneo e complexo, múltiplo, diferenciado, apesar de alguns traços comuns marcantes. Isso leva a repensar o fomento de um ensino enraizado na perspectiva for business, já que as condições do Nordeste demonstram ser bem diferentes de outras regiões.

O Nordeste viveu uma expansão do ensino superior nos últimos anos, com investimentos do Governo que não se estruturaram adequadamente. Nos anos 2000, o investimento nas universidades federais promoveu a expansão de vagas, a criação de novas instituições e a abertura de novos campi no âmbito do Programa Expandir e do Programa de Apoio a Planos de Reestruturação e Expansão das Universidades Federais (REUNI), instituído pelo decreto $n^{\circ} 6.096 / 2007$, cujo intuito era a ampliação do acesso e da permanência no ensino superior, aumentando o número de vagas na graduação, combatendo a evasão escolar e abrindo universidades pelas cidades de interior.

Também foi dada continuidade ao estímulo à iniciativa privada, que acelerou o processo de expansão de vagas e de instituições, recebendo alento adicional com o Programa Universidade para Todos (PROUNI), destinado à compra de vagas em instituições superiores privadas, o que veio a calhar diante do problema de vagas ociosas, enfrentado por várias dessas instituições (SAVIANI, 2010).

Por isso, é preciso compreender o ambiente de aprendizagem da região para promo- 
ver um ensino atual e contextual ao aluno de Administração, sem desconsiderar os impactos do passado e focalizando as influências da visão global.

\subsection{O AMBIENTE DE APRENDIZAGEM DA FORMAÇÃO DO ADMINISTRADOR}

O desenvolvimento de um ensino que supera a exposição de conteúdos estanques e disciplinas isoladas é quase inexistente. $\mathrm{O}$ ambiente de aprendizagem, por vezes, é desconsiderado, e o processo de ensino e aprendizagem, até pela distância entre teoria e prática e entre professor e aluno, fica mecanizado e desinteressante. Os estudiosos pouco têm avançado, efetivamente, nas pesquisas que se tornem aplicáveis ao processo do ensino em virtude de várias barreiras, inclusive, das diversas dimensões do ambiente de aprendizagem (LIMA; SILVA, 2015).

Santos (2009) mostra que os estudantes egressos do curso de Administração ingressam no mercado do trabalho, acreditando que terão sucesso rapidamente, mas se decepcionam quando enxergam diferenças em relação ao que aprenderam nas universidades. Eles se deparam com situações nas quais não conseguem tomar uma iniciativa por saberem executar a atividade.

Portanto, urge um entendimento maduro acerca do tratamento dado ao ambiente de aprendizagem dos alunos dos cursos de Administração no Nordeste, de modo que o curso possibilite a valorização da região como forma de permitir uma atuação profissional voltada para o seu desenvolvimento. Alguns relatos na literatura têm demonstrado que a abordagem do aprendizado pelos alunos está relacionada com as suas percepções sobre o ambiente de aprendizagem. Isto é, a alteração das condições do ambiente influencia a aprendizagem dos alunos (SANTOS, 2009).

Com efeito, esta pesquisa propõe três dimensões, cada uma com dois eixos, que servem de referência para compreender o ambiente de aprendizagem do administrador. As dimensões são as seguintes: Histórico-Política, EstruturalInstitucional e Cultural-Social, emergidas a partir de estudiosos dessa temáica.

\subsubsection{Dimensão histórico-política}

A história é analisada na perspectiva do ambiente em que o aluno está inserido. A inserção do curso de Administração no Nordeste surgiu para atender a uma demanda por funcionalismo público e, posteriormente, por profissionais para trabalharem nas empresas multinacionais que se instalavam em alguns estados. Nesse sentido, até a década de 1950, o Nordeste vivenciava um panorama de políticas agraristas, de um potencial setor algodoeiro, do cangaço e do domínio de famílias coronelistas, além de uma gestão pública baseada no patrimonialismo e das experiências já marcantes da seca em vários estados da região. Durante as décadas de 1940 e 1950, os cursos de Administração surgiram para suprir as necessidades de uma gerência científica que formasse a burocracia especializada, requerida para o desenvolvimento do País (FONSECA, 2012; NICOLINI, 2003).

No Governo de Juscelino Kubitschek (1956-1961), ocorreu a vinda de grandes empresas para o País. Logo, o ensinode Administração é resultante, tanto do desenvolvimento econômico promovido por Getúlio Vargas, como o impulso industrializante dado ao País pelo presidente JK (NICOLINI, 2003). O Governo de JK também é marcado pela criação do Grupo de Trabalho para o Desenvolvimento do Nordeste (GTDN), que apresentava uma proposta de política para promover o desenvolvimento regional, resultando na criação da Sudene (ARAÚJO, 2004).

No decorrer das décadas de 1970 e 1980 começavam a se consolidar os cursos de graduação em Administração no País, nas universidades públicas, mas com mudanças no foco dos cursos, que passaram a adotar uma vertente empresarial devido ao processo de industriali- 
zação aliado a um discurso desenvolvimentista decorrente da conjuntura política (COELHO, 2008). A região Nordesteapresentou dificuldades nos anos 1990 em se colocar como opção para os investimentos. Vários estados receberam investimentos relativos à relocalização de empreendimento da indústria de não duráveis, notadamente calçados, obrigados a reestruturar-se em razão da combinação da abertura comercial e da valorização cambial. No final da década de 1990 e início dos anos 2000, a região Nordeste retoma seus investimentos no setor manufatureiro e expande o número de unidades industriais, oportunizando empregos para os profissionais de Administração (MELO; SUBRINHO; FEITOSA, 2009).

Portanto, os cursos de graduação em Administração apresentam dificuldades em integrar o aluno ao contexto histórico e político local para que ele saiba em que ambiente aplicará as práticas organizacionais vistas nos conteúdos curriculares (LIMA; SILVA, 2015). Por isso, uma estrutura curricular em Administração elaborada a partir do conhecimento dos aspectos históricos da região e de suas influências políticas pode reconhecer melhor as necessidades locais para moldar as formas de ensinar os modelos teóricos e as práticas organizacionais.

\subsubsection{Dimensão estrutural-institucional}

Para Santos (2009), o ambiente de aprendizagem pode ser classificado quanto à sua estrutura e às suas atividades. A primeira relaciona-se, também, à parte física, o lugar onde as pessoas se utilizam de recursos a sua volta para dar sentido ao aprendizado e construir novos significados e favorecer a interação entre os membros envolvidos no processo de ensinoeaprendizagem. Já o segundo aspecto diz respeito aos instrumentos pedagógicos que operacionalizam a instrução no sistema educacional, tendo, na Administração,a função de aproximar o mundo real da gestão à sala de aula. Assim, Lima e Silva (2017) afirmam que o ambiente de aprendizagem é visto por meio de um conjunto de elementos que ligam as pes- soas e os artefatos em torno de um exercício que proporciona a condição, os meios e o apoio necessário para a experiência de aprendizagem.

A estrutura universitária é considerada um espaço de tomada de decisões formativas envolvendo agentes, condições, recursos, fontes de pressão, entre outros fatores. Essa estrutura abarca um espaço interno, a própria universidade e um espaço externo, correspondente às dinâmicas externas a ela, mas que afetam o seu funcionamento. Por isso, a universidade, em sua concepção institucional, é uma instância limitada e dependente, pois é capaz de fazer somente o que está ao seu alcance, partindo dos conhecimentos reais em que se articula (ZABALZA, 2004).

$\mathrm{O}$ ambiente estrutural-institucional envolve diversos aspectos complexos e, ao mesmo tempo, interligados entre si que afetam o ambiente de aprendizagem. A universidade é o lugar direto de formação superior do aluno e, por vezes, ela mesma distancia o aluno de outros componentes importantes para sua formação profissional (LIMA; SILVA, 2017; OLIVEIRA, 2014), sobretudo, quando ela ocorre em formato genérico, como o caso do ensino de Administração.

\subsubsection{Dimensão cultural-social}

Orientar o aluno sobre o ambiente social e cultural no qual ele se insere, relacionando-o à cultura regional, constitui-se em uma atividade importante em qualquer formação profissional. Merriam e Brockett (2007) comentam que a educação superior precisa ser compreendida por meio de um resgate global de influências externas até uma apropriação sobre o local. A culturaé um universo dotado de multiplicidade de significados, constituindo-se em uma natureza reestruturada pelas relações humanas (JARVIS, 2006).

Por meio da aprendizagem, esse autor alega que o aluno internaliza a cultura como um conceito ambíguo, por envolver elementos internos e externos, mas relevante para a realidade social, por meio da qual o indivíduo per- 
cebe e experiencia o mundo social. O processo de socialização implica uma aprendizagem que demonstra situações aceitas devido a questões morais e formas idiossincráticas.Sob essa ótica, o ensino de Administração não oferece uma interação social suficiente entre os alunos e com o professor no ambiente da sala de aula. Aliás,a preparação do aluno com seu meio social mediante a interação com representantes de diferentes organizações é deficitária (LIMA; SILVA, 2015).

Segundo Merriam e Bierema (2014), a cultura pode ser vista como um conjunto de diferentes línguas, culinárias, culturas corporativase lugares turísticos, ampliando a concepção do que envolve a gestão organizacional para que valorize características de organizações genuinamente locais. Doravante, Merriam e Brockett (2007) consideram o ambiente social centrado nas características culturais do ambiente de ensino-aprendizagem. Por isso, é importante reconhecer fatores de sexo, raça, etnia, entre outros, para saber como melhor ensinar os alunos a partir do ambiente cultural e social local do aluno.

\section{METODOLOGIA}

Este artigo utiliza uma abordagem qualitativa como balizadora para o alcance do seu objetivo, caracterizando-se por uma realidade vista como subjetiva, de caráter exploratório e descritivo por delinear uma formação diferenciada a partir do ensino de Administração, descrevendo o fenômeno como ele ocorre naturalmente, embasada na compreensão experiencial dos entrevistados (GRAY, 2012; STAKE, 2011).

A pesquisa se concentrou na realidade das instituições públicas de ensino superior federal ou estadual do Nordeste, pois foram nessas instituições que se introduziu, inicialmente, o curso de graduação em Administração em cada estado da região. A intenção foi selecionar professores que atuaram, significativamente, no ensino de Administração, contribuindo para seu estado e, consequentemente, para o desenvolvimento da região nordestina. Então, as entrevistas foram realizadas em 2015, presencialmente e via Skype após as confirmações dos professores convidados. Contudo, não foi possível obter êxito no contato com professores dos estados da Bahia e Maranhão. Ainda, Paraíba e Pernambuco contabilizaram dois docentes entrevistados cada, totalizando nove docentes.

Em relação à caracterização dos entrevistados consistiu em cinco homens e quatro mulheres. À exceção de um, todos possuíam a titulação de Doutor. Em geral, todos tiveram experiência profissional em ambas as esferas privada e pública, além da acadêmica. Aqueles que vivenciaram mais fortemente a Academia também estabeleceram vínculos internos à instituição, exercendo cargos administrativos. Por fim, alguns ainda continuam atuando como docentes, e outros se encontram aposentados.

Por razões éticas, os nomes dos docentes não foram identificados no decorrer da pesquisa, sendo codificados como DI até DIX. Foi utilizada a entrevista não diretiva formulada por Gray (2012). Este tipo de entrevista é usado para explorar um tópico em profundidade, mas as perguntas não costumam ser previamente planejadas.

O método de análise dos dados utilizado neste estudo foi a análise compreensiva e interpretativa dos dados desenvolvidos por Silva (2005), cujos passos seguidos foram: transcrição na íntegra das entrevistas; criação de protocolos de codificação a partir da leitura das entrevistas; agrupamento dos discursos codificados em categorias. Como esta pesquisa foi realizada com docentes, utilizou-se o seguinte código: "DN. n", em que $\mathrm{D}=$ Docente; $\mathrm{N}=$ Número do docente entrevistado e $\mathrm{n}=$ número do discurso.

Após essa etapa, teve início a definição das categorias correspondentes a cada dimensão do ambiente de aprendizagem. Essas categorias se definem por meio da relação entre os conceitos e as experiências relatadas pelos entrevistados. As categorias, assim, apresentam os discursos que resultam em significados. A ênfase apresentada na análise é a ilustração de discursos que contribuem com os resultados advindos das categorias abordadas. 


\section{DISCUSSÃO DOS RESULTADOS}

\subsection{RESULTADOS DA DIMENSÃO HISTÓRICO-POLÍTICA}

Esta dimensão apresenta as seguintes categorias: o desenvolvimento do ensino em Administração no Nordeste,perspectiva desenvolvimentista, relação acerca do ensino tradicional versus o moderno e a relação entre o Governo (federal ou estadual) e o Nordeste, já que são as instâncias responsáveis pelo ensino superior no País.

Os professores entendem que o curso de Administração surge antes da federalização das universidades. Assim, o desenvolvimento do ensino de Administração na região ocorre de forma heterogênea entre os estados, cuja idealização do curso foi realizada de forma difusa por professores de outras áreas do conhecimento, o que impacta no próprio sentido do que significa a Administração. A região implementa tal formação por meio da adoção de modelos de ensino importados do Sudeste. O desenvolvimento do ensino na região é marcado pela reforma universitária/cêntrica, com mudança do sistema seriado para crédito e ênfase na formação acadêmica do docente.

Então, nessa época, foi convocado um técnico, um consultor, inclusive, era um americano, chamado Rudolph Atcon, famoso por ser da OEA (Organização dos Estados Americanos) e estudioso da educação e veio fazer uma avaliação do funcionamento dos cursos no Brasil, que já tinha começado antes do golpe militar, e ele continuou nesse novo governo, e o relatório gera a reforma cêntrica. Ele fez a crítica do modelo brasileiro a partir da realidade dele, que era americana. $\mathrm{Eu}$ não culpo ele por esta reforma por isso. Então, para ele o Brasil não funcionava certo porque não seguia $o$ modelo norte-americano. Esse relatório foi, digamos assim, o esqueleto do que seria a reforma cêntrica, que era o sistema de créditos. Saia o mode- lo seriado e de escolas isoladas para todo mundo junto em um campus universitário. Então, a ideia dele era o modelo da escola americana, que era o que ele tinha conhecimento. Ele recomendou isso. Então, a reforma cêntrica foi obrigada no país e a aliança para o progresso financiava todo $\mathrm{o}$ investimento que o Brasil precisasse para copiar esse modelo. Teve todo o aporte financeiro para construir campus e contratar gente para implantar essa forma nova de funcionamento americanizado (DI.7).

Agora a reforma universitária é influência norte-americana. Isso é só um detalhe de mudança burocrática na estrutura dos cursos. Isso não diz respeito a mudanças no conteúdo curricular. É só a maneira como vai se organizar esse conteúdo e regular a obtenção disso pelos alunos. O sistema de créditos era pra dar mais flexibilidade e obedecia a um dos princípios da reforma universitária, o princípio da racionalização, assessorada pelo mesmo grupo da Aliança pelo progresso dos Estados Unidos (DV.10).

A adoção do modelo de ensino norte-americano do management, com uma orientação for business nas organizações, caracteriza a perspectiva desenvolvimentista aderida pelo País para a formação do administrador. Por sua vez, o Nordeste adota uma forma organizacional que difere de tal perspectiva. Desse modo, em paralelo, na ideia de desenvolver a região, cria-se o Banco do Nordeste, com êxitos em locais específicos e a Sudene, desfigurada, ao longo do tempo, pelos desvios dos seus projetos por interesses particulares de políticos.

Bom, esse modelo, chamado modelo americano de business é um modelo praticamente praticado no mundo inteiro. O que nós teríamos que fazer, e não fizemos suficientemente ainda, é a adaptação ou a brasileirização desse 
modelo, principalmente, em termos de Nordeste. Nós temos as nossas características, nossas peculiaridades e não basta você ter um ensinamento da arte da Administração baseados em modelos que são muito bem colocados nos Estados Unidos, na Europa, mas que aqui no Nordeste precisa ser aclimatado (DVIII.7).

A Sudene e o Banco do Nordeste tiveram até certo ponto alguma influência, principalmente, em Pernambuco e Ceará porque criaram mecanismos de incentivos fiscais e condições para que se instalassem empresas nesses estados. E com a classe política forte esses incentivos foram mais facilmente canalizados para grupos locais do que de outros Estados (DII.25).

Os docentes avaliam o ensino como tradicional quando há nele deficiência de artefatos já ultrapassados. Por outro lado, palavras como tecnologia, leitura, qualificação docente e pesquisa são elementos que sinalizam um ensino moderno $\mathrm{O}$ ensino tradicional e moderno envolve uma questão de cultura de ensino.

Eu não sei o que é ensino tradicional e moderno, eu não sei distinguir muita diferença porque se o ensino moderno é aquele em que a escola está cheia de aparatos tecnológicos eu não sei se dá muito resultado (DIV.32).

Particularmente, na pesquisa eu acho que a universidade não tem virado as costas para a realidade local não. Só que temos esse problema de transpor isso para o Governo. Agora, já na sala de aula eu acho que a gente acabou ficando muito teóricos em cima do conteúdo de fora, mas quando chega na parte da pesquisa a gente consegue olhar para o particular (DI.47).

Eu acho, na verdade, que a gente não avançou no essencial, que é no conteúdo verdadeiro. Precisamos ensinar o que eles precisam saber. Acho que a gente tá muito fraco nesse sentido (DVI.35).

Acho que não houve nenhum empe- nho especial, não. Mas isso depende de cada universidade também, né? De cada reitor e aí eu acho que não. Falando com relação à UFS, o Governo não faz muita coisa não já que também não cobra muita qualidade não, né? (DVI.29).

[...] A característica forte dos políticos daqui do estado é pegar recursos para resolver problemas pessoais deles. A universidade ficava era deficiente por falta de investimento do Estado, e os políticos alegam que o estado é pobre e os recursos não chegam, mas é negligência mesmo dos políticos (DIX. 4).

Novamente eu tenho que lamentar porque eu acho que o Governo não tem dado à área de Administração a sua devida importância. Então, se faz muito mais Administração na base do jeitinho, não é? Onde todo mundo acha que sabe administrar, que todo mundo tem alguma coisa de administrador, e tem de médico e de louco também, né? E, portanto, resolve deixar de lado a figura do administrador. Eu acho que se os Governos percebessem a importância de ter em seus quadros pessoas com formação específica em Administração, nós seríamos um país em outra situação (DVIII.6).

Percebe-se a falta de uma interação entre o Governo e a região, aproximando-se das universidades apenas quando surge a necessidade de acordo político em função do orçamento universitário ser substancial na região. As palavras menosprezado, atrasado e ignorante caracterizam a visão que o Governo tem com o Nordeste. Sendo assim, a relação entre Governo e Nordeste se restringe aos planos de Governo e a uma atuação insuficiente e superficial do Ministério da Educação junto às universidades da região para tratar de uma estrutura curricular baseada em aspectos do ambiente de aprendizagem. Os próprios projetos de interiorização das universidades na região aconteceram de maneira desorganizada e descontextualizada. 


\subsection{RESULTADOS DA DIMENSÃO ESTRUTURAL-INSTITUCIONAL}

Essa dimensão considera as seguintes categorias: posicionamento das universidades na região, vertentes da Administração, perfil do aluno e relação entre currículo e ação docente.

Os professores enxergam o posicionamento das universidades na região como falho e amador, dificultado pelo fator relacional e pela falta de gestão. É preciso articular melhor planejamento, autonomia e financiamento das universidades para beneficiar mais a região, conforme assinalam Lima e Silva (2017). Logo, o papel da universidade é olhar para o específico, sendo necessárias políticas institucionais de motivação para os envolvidos na estrutura universitária. Quanto ao ensino de Administração, perde-se com debates político-partidários nos Departamentos.

[...] E a universidade ela peca, ela não peca sozinha, é um pecado meio coletivo, junto com o Governo do Estado e também do município da cidade, que não desenvolvem a sociedade. A universidade por si só tem uma coisa encastelada, o pessoal até chama de torre de marfim. Então, a gente tem dificuldade de sair para se colocar mais próxima das organizações que estão ao redor da universidade. O Estado vê a universidade lá como a representante do poder central, que é um viés político. Embora muita gente do estado, muito decisor do estado, seja professor da universidade, mas é uma dificuldade relacional muito grande e isso depende muito de quem esteja no poder (DI. 44).

Eu saí na compulsória e nunca vi da época que a universidade foi tomada pelos centros uma preocupação real pelo ensino, tudo gira por questões políticas sem sentido. As reuniões departamentais passaram a ser apenas discussões ideológicas político-partidárias que não se centravam na melhoria da qualidade do ensino (DII.12).
Uma das vertentes da Administração foi bem forte no surgimento do ensino em Administração no Nordeste, que é a pública devido à debilidade empresarial da região. A vertente empresarial adentrou na região a partir da perspectiva desenvolvimentista via influência da Sudene na região. A vertente pública se limita, posteriormente, à disciplina no curso de Administração. Há docentes que consideram importante a distinção das vertentes na formação do administrador, já outros acreditam que as duas vertentes devem se fundir no ensino em Administração.

O ensino de Administração, no Brasil, começou através de uma escola do serviço público, tinha uma conotação pública. E no Rio de Janeiro começou na FGV como Administração Pública, só depois que ela passou a ter também o de Empresas. Em São Paulo, que tinha um viés industrial muito grande, aí se deu ênfase ao ensino voltado para as indústrias. No Nordeste, algumas décadas atrás, havia muito pouca indústria, então, não havia interesse por ensinar Administração de Empresas. [...] À medida que o Nordeste foi se industrializando, começou a ter bipolaridades, cursos de Administração passando a carregar mais em disciplinas da área de empresas em vez de pública. A Bahia mesmo começou e continua ainda hoje muito forte em Pública (DIV.16).

[...] O serviço público também pode ser um espaço de trabalho pro meu conhecimento técnico, mas era tudo muito atrasado, era mal visto. O curso mesmo tinha uma ou duas disciplinas e nem era incentivado pelos professores porque estes atuavam mais no privado mesmo. Mas seria necessário fortalecer e melhorar a formação em Administração Pública (DIII.8).

Os docentes avaliam que os alunos antigamente eram mais comprometidos e participativos na vivência acadêmica e com criticidade sobre a política, mas sem expectativas quanto 
ao seu futuro. Por sua vez, os alunos atuais são jovens e ansiosos quanto ao seu futuro profissional, e também são desinteressados e desestimulados. São alunos que querem um ensino mastigado, pronto e imediato. Os professores retratam que o perfil do aluno difere quanto à classe social, ao turno do curso, à instituição (pública ou privada) e à região geográfica (de fora da região, da capital ou do interior). As universidades acabam não levando em consideração esse perfil como forma de melhorar o processo formativo do aluno a partir do seu ambiente de aprendizagem, que é influenciado pelo seu perfil.

Agora o quê que a gente via ou continua vendo, os alunos de 30 anos atrás eram muito mais dedicados porque eles tinham mais tempo para a instituição, para o curso, eram mais estudiosos [...]. Eu acho que naquela época os alunos estavam mais disponíveis ao aprendizado, talvez pra esse modelo de aprendizagem professor e aluno. Hoje a gente vê que tem muita coisa na cabeça do jovem, que ele não tem muito tempo pra nada, ele quer tudo mastigadinho, pronto e muito imediatista. Ele não consegue perceber que ele precisa ter uma base pro futuro, e que essa base quem vai dar é a gente, o curso de graduação. Claro que não são todos, mas grande parte é assim mesmo. É simplesmente passar (DVII.15).

Percebe-se que a relação entre currículo e ação docente é deficitária porque o currículo não abrange singularidades do contexto, e os professores não se comprometem por melhorias na estrutura curricular para contribuir com o processo formativo do aluno no ensino de Administração. O currículo é conduzido por questões de legalidade, de modismo e de interesse particular de docente. Porém, há professor que alega que o currículo deve focalizar a localidade, já outro acredita ser um currículo incapaz de trabalhar com especificidades da região.
[...] eu sou um crítico muito grande dos nossos projetos pedagógicos porque nós estamos ainda muito parados no passado, da forma como as coisas eram feitas, na base do professor ir pra sala de aula e ficar na falação e trazer suas experiências, que são muito importantes, trazer a teoria, que é muito importante, mas hoje você precisa de muito mais um link entre professor e aluno mais forte (DVIII.11). Tem muito professor que não se empenha com o ensino. As pessoas não se comprometem, não cobram do aluno e não exigem. Não querem ter muito trabalho, a verdade é esta. É muito fácil passar nas disciplinas. Dar 30\% das aulas e faz qualquer trabalhinho e passa. Mas aí tem que ter um trabalho muito pesado e hoje temos sala enormes, né? Os professores não têm como dar feedback com turmas com mais de 60,70 alunos numa turma. Eu acho mesmo assim, que tinha que ser um pouco mais rigoroso (DVI.34).

[...] quem são os professores do curso de Administração? Na verdade, isso se aplica a todos os cursos da universidade, que são professores que nunca fizeram uma disciplina de educação, nunca estudaram nada, nada de educação, nada de metodologia, currículo e planejamento escolar. Foi um profissional brilhante porque trabalhou em uma empresa, tem domínio do conhecimento, mas transferir conhecimento é diferente. Didaticamente não há uma preparação. [...] (DI.17).

É necessário melhorar a ação docente para que ele se envolva mais com a composição curricular do curso, pois afeta a formação qualificada do aluno de Administração. Contudo, o professor se enxerga sobrecarregado com o volume de atividades e acaba desprestigiando a esfera do ensino, prejudicando o processo de aprendizagem dos discentes. Ademais, o docente não recebe a devida preparação didática para estar em sala de aula. 


\subsection{RESULTADOS DA DIMENSÃO CULTURAL-SOCIAL}

Essa dimensão apresenta as seguintes categorias: a regulamentação da sua profissão, contexto da região para formular uma noção mais precisa do ambiente de aprendizagem do estudante, desafios da formação do administrador na região e a identidade desse ensino, sobretudo na região Nordeste.

Os professores revelam que a regulamentação da profissão ocorreu no regime militar sem a participação dos agentes envolvidos com a formação do administrador, desencadeando-se na criação dos Conselhos. Essa regulamentação é vista como ambígua e um engano porque não resultou em nenhuma melhoria substancial para a formação do aluno. Além disso, a atuação dos Conselhos tem deixado a desejar, sendo avaliados como ineficientes, classistas e por pensarem em benefício próprio, mas da categoria profissional. Aliás, isso é acentuado pela fragilidade de definição do que envolve a Administração.

A questão de espaço legal do administrador ainda hoje é problemática porque o nosso espaço é constantemente invadido por profissionais de outras áreas. E os conselhos vão pra justiça e nem sempre conseguem que suas demandas sejam aceitas. Então, nós continuamos concorrendo com outros profissionais que invadem nosso campo de atuação. Eu acho que os conselhos deveriam atuar mais [...] (DIV.30).

[...]. Eu acho que a atuação do Conselho ainda é fraca, mas é dificultada pela própria dificuldade histórica de você definir o campo de trabalho de Administração (DI.59).

O contexto da região é caracterizado como pobre, de empresas de pequeno e médio porte, de cunho familiar, além das cooperativas e da esfera pública. O aluno, desde o surgimento da Sudene, tem gerado expectativas sobre sua formação, mas acaba por enveredar pelos concursos públicos por enxergar uma maior oferta na região. Eles buscam uma estabilidade, impulsionados ainda pelo sentimento de inferioridade das pessoas da região. Os professores precisam oferecer uma formação alinhada com esse contexto do aluno, conduzindo-o a uma consciência analítica exercida para a vida. Os docentes alegam que o currículo é a forma de viabilizar essa articulação do estudante com o contexto, ou seja, com o seu ambiente de aprendizagem local.

$\mathrm{O}$ aluno aqui continua ainda tendo o sonho de ser funcionário público também. Daí muitos alunos fazem concurso para ensino médio durante o curso e depois fazem para superior. Mas aqui muitos querem ser servidor público porque o Governo ainda é o grande empregador da região. Não tem tantas empresas (DVII.40).

Nós temos que assenhorarmos das nossas necessidades, das nossas características, da nossa cultura, e trabalharmos Administração voltada para o desenvolvimento disto. Por exemplo, uma crítica que eu sempre faço com relação à região Nordeste é aquela velha história da seca. Todo mundo fala da seca do Nordeste. Ora, a seca no Nordeste está posta, ela faz parte da região, a região é seca, ela não está seca ou não está molhada eventualmente. Ela é uma região seca naturalmente e nós precisamos, portanto, de pessoas que quando estiverem tanto na iniciativa privada como no serviço público que tenham esta formação também em termos culturais, de conhecimento da região pra buscar soluções adequadas à situação, que é algo da região. E não que tenha conhecimentos simplesmente a modelos importados [...] (DVIII.16). Há problemas administrativos a se resolver que são só da região, do estado, que entre eles são diferentes. Pode ter problemas nas empresas e 
órgãos públicos que é só daqui de Pernambuco que se difere dos da Paraíba. Aqui nós temos a tradição de entreposto comercial e de mascates, que são os ambulantes fortíssimos em Recife [...] (DV.21).

$\mathrm{O}$ investimento na área do empreendedorismo para o Nordeste é considerado como um dos desafios da formação do administrador na região, pois o empreendedorismo consegue trazer uma conotação contextual para o ensino em Administração da região e, assim, estimular uma formação regionalizada assinalada pelos entrevistados. Porém, os esforços dos envolvidos no ensino na busca pela aproximação do ambiente do aluno e pela revalorização do ensino em Administração, por vezes, recaem no marasmo e no descrédito.

Os desafios, na verdade, é pensar mais em pequenas e médias empresas. Mas quando se pensa nisso o carro-chefe é o empreendedorismo. Chegou um certo momento na nossa instituição que nós colocamos como algo transversal, implantamos uma interdisciplinaridade no currículo, todas as nossas disciplinas do curso, isso é real mesmo, você tem que ter o empreendedorismo (DIII.30).

$\mathrm{Na}$ verdade, a gente tem que conseguir influenciar mais onde a gente está, principalmente, com essa interiorização que as federais fizeram. $\mathrm{Eu}$ tenho que conseguir fazer com que o aluno de uma federal interiorizada ele olhe pra sua própria cidade, pra sua região, seu local como uma possibilidade de crescimento real pra ele e para a região. Mas também a gente se depara ainda com cada escassez desses locais. [...] (DVII.54).

Percebe-se que a identidade do ensino de Administração tem sido caracterizada como um blefe, tênue e vaga, pois uma transformação cultural demanda tempo. Os cursos ainda estão apegados ao modelo de retórica e pragmatismo, dificultando um aprimoramento da imagem identitária do ensino de Administração, sobretudo, voltado para a problematização constatada na localidade.

É muito pouca essa preocupação em contribuir pra o Estado ou região, mas também até que ponto nós estamos provocando essas pessoas? Eu lembro que em 1987 eu comecei a discutir com alguns colegas, um deles inclusive estava recentemente no Conselho Regional de Administração, nós começamos a discutir um projeto de exalunos da universidade, atrair eles para participarmos dessa relação sociedade e universidade. Esse projeto nunca conseguiu ir a frente, outras pessoas também já tentaram, mas sempre esbarra, eu não sei, um certo marasmo. A gente começa a pensar se vai atrair alguém, mas vai dar muito trabalho, como é que eu vou fazer, o que eu vou oferecer, etc. E termina ficando pelo meio do caminho (DVIII.46).

A identidade da gente está bem fraca, mas não sei se isso vai melhorar porque mudança de cabeça, de formação, de cultura é muito lenta. Estamos caminhando, ne? Os professores tem que mudar, mas também os empresários tem que sentir necessidade da gente, de administradores em suas empresas. Eles têm que mostrar qual profissional eles querem porque nem eles mesmo, muitas vezes, não sabem o que querem. Eles não sabem nem o que estão avaliando, às vezes, nos candidatos (DVII.62).

Eu vejo que aqui no Nordeste o ambiente é bem diferente. Em Recife mesmo tem um parque industrial muito maior que aqui, lá o aluno vai ter uma identidade diferente provavelmente dos daqui do Piauí. A identidade daqui é mais para concurso, os alunos não pensam que 
vão trabalhar como administradores. É preciso melhorar ou se criar efetivamente a reserva de mercado para o administrador para que a gente tenha um administrador com identidade de administrador, [...] Existe um profissional com conhecimentos de Administração, mas ainda não existe uma identidade do administrador (DIX. 10).

Tais mudanças exigem um compromisso, principalmente, do professor, que já aponta a sua identidade profissional como decaída e precarizada para se comprometer com o desenvolvimento de tal identidade. Sabe-se que a construção da identidade do ensino não depende somente do professor e do aluno. Isto é, depende também dos empresários e da comunidade local que se inserem no ambiente de aprendizagem do ensino de Administração da região. Destaca-se que essa crise identitária não se deve apenas à adoção do modelo do management, mas ocorre devido a uma composição curricular eclética, que impede um real trabalho de interdisciplinaridade por meio de disciplinas que correspondam a uma formação qualificada do administrador.

\section{REFLEXÕES}

Doravante, as universidades da região e, consequentemente, o ensino de Administração, foram afetadas por influências políticas que, por vezes, inibiram uma atuação mais efetiva sobre a região para desenvolvê-la econômica e socialmente. Caso a formação do administrador atentasse mais para as particularidades da região e para o seu mundo de trabalho, poderia ser mais significativa. O Nordeste é heterogêneo culturalmente, caracterizado por algumas singularidades nas formas organizacionais existentes que afetam os setores produtivos. Uma visão ampla sobre as vertentes da Administração poderia considerar o empreendedorismo, o cooperativismo, a gestão de desenvolvimento local e das micro e pequenas empresas como formas de também possibilitam o desenvolvimento regional por meio da profissão do administrador.

Para isso, torna-se fundamental compreender a profissão de Administração desde sua regulamentação para perceber que a sua identidade ainda é fraca perante a sociedade, principalmente, quando pensada de forma regional. Construir uma identidade que aproxime o aluno da sua formação é fundamental, uma vez que o ensino em Administração deve refletir o ambiente de aprendizagem. Sem reconhecimento e definição da profissão, a qualidade do ensino e a formação condizente com o que está no entorno do ambiente de aprendizagem do aluno ficam comprometidas.

O ensino de Administração precisa ampliar e adequar suas estratégias de ensino ao ambiente de aprendizagem da região. Assim, propõe-se uma formação regionalizada para o administrador como forma de permitir essa relação entre o ensino e o ambiente local. No entanto, a visão vaga sobre a identidade do ensino de Administração inibe a sua credibilidade sobre a prática organizacional local, o que demanda uma transformação da percepção cultural regional sobre o papel do administrador no Nordeste.

Assim, há desafios, conforme quadro 1 , a serem enfrentados nas dimensões do ambiente de aprendizagem, de modo que promovam uma maior articulação no processo formativo para possibilitar uma atuação profissional do administrador consistente e consciente sobre o desenvolvimento do Nordeste. 
Quadro 1 - Desafios das dimensões do ambiente de aprendizagem

\begin{tabular}{|c|c|}
\hline DIMENSÕES & DESAFIOS \\
\hline Histórico-Política & $\begin{array}{l}\text { - Equilibrar as condições socioeconômicas entre } \\
\text { os estados, proporcionando oportunidades de } \\
\text { trabalho equitativas para o administrador. } \\
\text { - Construir uma autonomia sobre modelos de } \\
\text { ensino que se coadunem com a realidade } \\
\text { contextual. } \\
\text { - Rever ações positivas da reforma universitária na } \\
\text { região para aprimorar o processo formativo. } \\
\text { - Clarificar o que corresponde ao ensino tradicional } \\
\text { e moderno em Administração na região. } \\
\text { - Avaliar a contribuição da Sudene para a formação } \\
\text { do administrador. } \\
\text { - Estabelecer um contato como MEC, independente } \\
\text { do partido do Governo, para discussão de pauta } \\
\text { específica sobre a realidade da região frente ao } \\
\text { ensino de Administração. }\end{array}$ \\
\hline Estrutural-Institucional & $\begin{array}{l}\text { - Definir orientações de base para uma gestão } \\
\text { universitária no Nordeste coerente com a } \\
\text { realidade contextual. } \\
\text { - Discutir um projeto sobre a autonomia } \\
\text { universitária com responsabilidades explícitas } \\
\text { sobre o uso dos recursos para os cursos. } \\
\text { - Revalorizar a docência para a esfera do ensino. } \\
\text { - Identificar as formas organizacionais da região } \\
\text { que podem ser configuradas como de atuação do } \\
\text { administrador. } \\
\text { - Incentivar os alunos a desenvolver sua região } \\
\text { a partir de uma formação regionalizada em } \\
\text { Administração. } \\
\text { - Estruturar um currículo adequado às } \\
\text { peculiaridades do Nordeste, considerando as } \\
\text { diretrizes que regulamentam a profissão. }\end{array}$ \\
\hline Cultural-Social & $\begin{array}{l}\text { - Sensibilizar as pessoas da região a uma } \\
\text { consciência de pertencimento. } \\
\text { - Ajustar o papel do administrador a partir da } \\
\text { regulamentação da profissão para uma atuação } \\
\text { mais apropriada ao ambiente local. } \\
\text { - Modificar a imagem dos Conselhos perante os } \\
\text { alunos por meio da redefinição de sua atuação na } \\
\text { promoção da profissão. } \\
\text { - Designar responsabilidades específicas aos } \\
\text { Conselhos regionais em articulação com as } \\
\text { universidades. } \\
\text { - Construir uma identidade forte da profissão } \\
\text { no Nordeste conforme a realidade do campo } \\
\text { organizacional. } \\
\text { - Criar um percurso formativo para o aluno de } \\
\text { Administração a partir da integração entre as } \\
\text { universidades da região. }\end{array}$ \\
\hline
\end{tabular}

Fonte: elaboração própria (2019). 


\section{CONSIDERAÇÕES FINAIS}

Este estudo abordou a formação do administrador no Nordeste do Brasil por meio das dimensões histórico-política, estrutural-institucional e cultural-social. O trabalho contribuiu com o resgate histórico do ensino de graduação em Administração do Nordeste. Além disso, foi proposta uma formação mais regional para o aluno a partir do seu ambiente de aprendizagem. Por fim, este estudo pode despertar o interesse de pesquisadores a entender o ambiente de aprendizagem e sua contribuição para a formação regionalizada em outras regiões, resgatando a história do ensino em Administração, até para identificar as similaridades e diferenças. Ainda, recomendam-se estudos voltados à proposição de itinerários formativos, a partir das peculiaridades do ambiente de aprendizagem da região, que podem empreender para o avanço nos processos de formação do administrador.

O resgate do ensino de Administração, a partir de uma perspectiva regional, pode contribuir para criar uma identidade da profissão na região, a partir da formação de um profissional que atenda aos anseios da comunidade local, considerando a Administração como um sistema que agrega valor não apenas às organizações públicas, privadas e do terceiro setor, mas principalmente para a sociedade.

\section{REFERÊNCIAS}

ARAÚJO, T. B. Northeast, Northeasts: whatnortheast? Latin American Perspectives, V. 31, n. 2, p. 16-41, 2004.

COELHO, F. S. Uma radiografia do Ensino de Graduação em Administração Pública no Brasil (1995-2006). In: ENANPAD, 32., 2008, Rio de Janeiro/RJ. Anais [...]. Rio de Janeiro, 2008.

COELHO, F. S.; NICOLINI, A. M. Uma Contribuição à História do Ensino de Graduação em Administração Pública no Brasil (19521994): proposta de periodização e análise de um dos estágios de construção. In: ENANPAD,
34., 2010, Rio de Janeiro/RJ. Anais [...]. Rio de Janeiro/RJ, 2010.

COLLI, W.; CHAGAS, P. B. Representações sociais dos estudantes de administração sobre o ensino universitário: estudo em uma universidade pública de Paranavaí. Revista Foco, v. 11. n. 1, 2018.

FISCHER, T. M. D. O Ensino de Administração Pública no Brasil, os ideais de desenvolvimento e as dimensões da racionalidade. 1984. 322f. Tese (Doutorado em Administração) - Faculdade de Economia e Administração da Universidade de São Paulo, USP, São Paulo-SP, 1984.

FISCHER, T. A formação do administrador brasileiro na década de 90: crise, oportunidade e inovações nas propostas de ensino. Rev. Adm. púb., Rio de Janeiro, v. 27, n. 4, p. 11-20, out./dez. 1993.

FONSECA, P. C. D. A Revolução de 1930 e a Economia Brasileira. Revista EconomiA, set./ dez. 2012.

GIBBS, G. Análise de dados qualitativos. Porto Alegre: Artmed, 2009.

GRAY, D. E. Pesquisa no Mundo Real: métodos de pesquisa. 2. ed. Porto Alegre: Penso, 2012 .

INEP (Instituto Nacional de Estudos e Pesquisas educacionais Anísio Teixeira). Censo da Educação Superior. Matriculados em Administração. 2015.

JARVIS, P. Towards a comprehensive theory of Human Learning: lifelong learning and the learning society. [S.l.]: Routledge, 2006.

LIMA, T. B.; SILVA, A. B. O ambienteestructural e institucional do ensino de AdministraçãonaregiãoNordeste do Brasil. Administração: Ensino e Pesquisa (RAEP/ 
ANGRAD), Rio de Janeiro, v. 18, n. 2, maio/ ago. 2017.

LIMA, T. B.; SILVA, A. B. O ambientehistórico e politico do ensino de AdministraçãonaregiãoNordeste. In: ENCONTRO DE ENSINO E PESQUISAEMADMINISTRAÇÃO E CONTABILIDADE: ENEPQ/ ANPAD, 5., 2015, Salvador/BA. Anais [...]. Salvador/BA, 2015.

MELO, R. O. L.; SUBRINHO, J. M. P.; FEITOSA, C. O. Indústria e Desenvolvimento em Sergipe. REN (RevistaEconômica do Nordeste), v. 40, n. 2, 2009.

MERRIAM, S. B.; BIEREMA, L. L. Culture and Context, theory and practice in adult learning, chapter twelve. In: MERRIAM, S. B.; BIEREMA, L. L. Adult Learning: linking theory and practice. San Francisco: Jossey-Bass, 2014.

MERRIAM, S. B.; BROCKETT, R G. The profession and practice of adult learning: an introduction. San Francisco: Jossey-Bass, 2007.

NICOLINI, A. Qual será o futuro das fábricas de administradores? RAE, v. 3, n. 2, 2003.

OLIVEIRA, A. L. Os reflexos da experiência formativa na vida profissional do administrador:uma investigação a partir da ótica de egressos da educação superior privada do sul de Minas Gerais. 2014. 165 f. Tese (Doutorado em Administração) - Universidade Federal de Lavras, Lavras, MG, 2014.

RIBEIRO, D. A. Trajetória institucional da universidade brasileira: a UFBA como reflexo e modelo. 2011. 294 f. Tese (Doutorado em Administração) - Escola de administração. Universidade Federal da Bahia, Salvador, 2011.

SANTOS, J. A. Learning Environments in Management Education: in Search of Meaning. In: ENANPAD, 33., 2009, São Paulo. Anais
[...]. São Paulo, 2009.

SAVIANI, D. Expansão do ensino superior no Brasil: mudançase continuidades. Poíesis Pedagógica, v. 8, n. 2, ago./dez. 2010.

SILVA, A. B. A vivência de conflitos entre a prática gerencial e as relações em família. 2005. Tese (Doutorado em Engenharia de Produção) - Universidade Federal de Santa Catarina, Florianópolis, 2005.

STAKE, R. E. Pesquisa Qualitativa: estudando como as coisas funcionam. Porto Alegre: Artmed/Penso., 2011.

VALE, M. P. E. M.; BERTERO, C. O.; SILVEIRA, R. A. Caminhos diferentes da americanização na educação em Administração no Brasil: a EAESP/FGV e a FEA/USP. Administração: ensino e pesquisa, v. 14, n. 4, p. 837$872,2013$.

ZABALZA, M. A. O ensino universitário: seu cenário e seus protagonistas. Porto Alegre: Artmed, 2004. 